\title{
Um Senhor de Engenho a Serviço do Rei da Espanha: A América Portuguesa e a Monarquia Universal no Século XVII
}

\author{
A Sugar Plantation Lord in the Service of the Spanish \\ King: Portuguese America and the Universal Monarchy \\ in the XVIIth Century \\ Un Hacendado del Azúcar al Servicio del Rey de \\ España: La América Portuguesa y la Monarquía \\ Universal en el siglo XVII
}

Kalina Vanderlei Silva ${ }^{a}$

\begin{abstract}
Resumo: Procuramos, neste artigo, traçar a trajetória de um senhor de engenho da capitania da Paraíba, Jorge Lopes Brandão, que, após a invasão holandesa das capitanias do norte do Estado do Brasil, colocou-se a serviço de Felipe IV na Guerra dos Trinta Anos. Seguindo seu percurso, procuramos reconstruir fragmentos das conexões da América açucareira portuguesa no cenário da Monarquia Universal dos Habsburgo.
\end{abstract}

Palavras-chave: Brasil Colônia - monarquia universal espanhola - século XVII

Abstract: This article tries to reconstruct the trajectory of a sugar plantation lord from Paraiba's captaincy, Jorge Lopes Brandão, who, after the Dutch invasion, fought in the 30 years war. The main objective is to understand better the complex dialogue between the Sugar Society and the Habsburgo's Universal Monarchy.

Keyword: Universal Monarchy. Colonial Brazil. XVIIth century.

Resumen: Buscamos en este texto, reconstruir la trayectoria de un hacendado del azúcar de la capitanía da Paraíba, Jorge Lopes Brandão, quien después de la invasión holandesa en las capitanías del norte de Brasil, se puso al servicio de Felipe IV, en la Guerra de los Treinta Años. Siguiendo el personaje, buscamos reconstruir las conexiones establecidas entre la América portuguesa azucarera en el escenario de la Monarquía Universal de los Habsburgo.

Palabras clave: Monarquía Universal. Brasil Colonial. Siglo XVII.

a Professora da Universidade de Pernambuco. Doutora em História pela UFPE. <kalinavan@uol. com.br>. 


\section{Introdução}

Em 1638, na esteira da Guerra dos Trinta Anos, as tropas de Felipe IV de Espanha combateram os soldados franceses de Luís XIII na batalha de Fuenterrabía, cidade basca na fronteira do reino de Navarra. Nessa ocasião, entre os muitos fidalgos de diferentes origens que lutaram pela Coroa habsburga, estava um vassalo da distante América portuguesa, Jorge Lopes Brandão, senhor de engenho da Paraíba. Personagem que logo depois se poria também a serviço do rei na repressão à revolta da Catalunha, reforçando sua lealdade à Madri mesmo após a restauração portuguesa, tornando-se uma representação ideal da inserção das elites coloniais da América açucareira portuguesa no cenário intercontinental da Monarquia Católica.

Enquanto senhor de engenho, e veterano das guerras holandesas no Estado do Brasil, Jorge Lopes Brandão integrava um grupo já bastante estudado pela historiografia. Por outro lado, sua atuação nas guerras europeias ilustra uma faceta desse grupo ainda pouco examinada e que aponta para novos ângulos de observação da complexa relação entre centro e periferias nos impérios ibéricos. É essa faceta que pretendemos focar aqui usando sua trajetória de vida como ponto de partida para a análise de seu grupo social: a elite açucareira da América portuguesa. Um grupo que se consolidou enquanto elite política durante o governo dos Habsburgo em um processo, entretanto, que ainda permanece em grande parte desconhecido da historiografia.

Tentando reconstruir esse contexto é que nos debruçamos sobre a correspondência administrativa que fala sobre Jorge Lopes Brandão e seus serviços a Felipe IV e que nos permite traçar sua trajetória desde a Paraíba até a Catalunha, esclarecendo um pouco mais da relação dos senhores do açúcar com a Monarquia Católica, assim como das próprias estruturas sociais da América açucareira. Portanto são dois os cenários que devemos investigar: aquele da guerra de resistência luso-espanhola contra a invasão da WIC (West-Indische Compagnie, a Companhia Holandesa das Índias Ocidentais) às capitanias do norte na primeira metade do século XVII, e aquele da crise do império espanhol, com a Guerra dos Trinta Anos e a rebelião da Catalunha em meados do mesmo século. Dois cenários percebidos aqui a partir de sua inserção no mesmo e amplo arcabouço da Monarquia Católica, cujos limites serviam de palco para uma diversidade de interações culturais e políticas que, desde a ascensão de Felipe II ao trono português, abarcavam também a América portuguesa. 
Dessa forma, a noção seiscentista de Monarquia Católica se torna basilar para o desenho dos limites de nossa história. Congregando os reinos subordinados a Felipe II de Espanha a partir de 1580, ela representava uma noção que ia além da simples definição territorial, ou da submissão a um soberano. Para Gruzinski (2003, p. 324-325), ela teria sido não apenas o palco da primeira economia-mundo, mas também das primeiras estruturas burocráticas a operarem em escala planetária, com funcionários e governadores cuja influência poderia alcançar territórios bem exteriores a suas jurisdições, tais como Salvador Correa de Sá, e com redes sociais e culturais sustentadas pela circulação de pessoas e ideias que colocavam em direta interação tradições culturais ibéricas com aquelas de regiões tão distantes quanto a América portuguesa, Goa e Manila.

Mas se a Monarquia Católica dificilmente pode ser considerada um tema novo, objeto que foi de clássicos ocidentais como O Mediterrâneo, de Fernand Braudel (1953), e de uma volumosa historiografia em língua espanhola, inglesa e alemã que inclui desde John Elliott (2007) e John Lynch (2005), até Fernando Bouza Álvarez (2000), Rafael Valladares (2006), Bartolomé Yun Casalilla (1999) e Peer Schmidt (2013), no que diz respeito à brasileira, ela permanece praticamente inexplorada, com importantes exceções como os trabalhos de Eduardo França Paiva (1997) e Ana Paula Megiani (2004). Em seu lugar, os historiadores que têm o século XVII como recorte privilegiado optaram, classicamente, pelo chamado Brasil holandês, principalmente aqueles cujo olhar se dirigia à América açucareira. Assim, enquanto a resistência aos holandeses se tornou um tema paradigmático para essa historiografia, como posto no clássico Olinda Restaurada, de Evaldo Cabral de Mello (1998), a relação das capitanias açucareiras, no mesmo período, com os reis espanhóis ainda se apresenta como extremamente lacunar, e com exceção do texto clássico de Joaquim Serrão (1968), toda a rede de conexões sociais, culturais e políticas que envolvia os senhores de engenho com a administração habsburga permanece em aberto e só agora começa a ser desvendada (Santos Pérez, 2012).

Nesse sentido é que nos voltamos para os documentos elaborados por e para o Conselho de Portugal, que administrava o lado português do império Habsburgo para os Felipes, no intuito de acessar indícios e fragmentos que possibilitem a reconstrução das conexões dessa rede; uma reconstrução montada a partir das trajetórias de protagonistas como Jorge Lopes Brandão. 


\section{O personagem e a América açucareira}

O cenário original de Jorge Lopes Brandão, a capitania da Paraíba, deveu a efetivação de sua conquista, na década de 1580 , à política filipina, que enviara tropas portuguesas, indígenas e espanholas reunidas em Pernambuco e postas sob o comando espanhol para agir contra franceses e potiguares (Gonçalves, 2007, p. 23-47; idem, 2008, p. 1-14). Um sucesso cantado nas páginas do Sumário das Armadas, frisando o quanto tal conquista fora uma vitória de Felipe II de Espanha (Sumario das Armadas, [1585] 1996). E uma vez concluída a guerra contra os potiguares, o estabelecimento colonial na capitania foi consolidado com a fundação, em 1585, da cidade de Filipeia de Nossa Senhora das Neves, por ordem do mesmo rei (Moura Filha, 2004, p. 136), também não demorando a que os engenhos fossem se espalhando pela região, até o momento em que, na década de 1630 e após invadir Olinda e o istmo do Recife, as forças da holandesa WIC alcançaram a Paraíba (Nascimento, 2008, p. 87, 91, 106).

A imediata resposta que essa invasão suscitou nas elites locais e nos comandantes luso-espanhóis estabelecidos em Pernambuco e Bahia deu início à guerra que se estenderia até 1637 , com os senhores do açúcar se colocando às ordens de Matias de Albuquerque, comandante nomeado por Felipe IV. No entanto, em 1635 as forças de Albuquerque foram derrotadas em um dos últimos baluartes católicos na área disputada, o Arraial do Bom Jesus, o que abriu as portas para a consolidação do poder da WIC na região, cimentado, pouco depois, pela conquista de Porto Calvo, a última posição da resistência a norte do rio São Francisco. Essa dupla derrota levou à retirada massiva de colonos de Pernambuco e das capitanias anexas para a Bahia, encabeçada por um dos principais comandantes imperiais no mundo do açúcar, o Conde de Bagnuolo, em um episódio que marcaria a cisão da elite açucareira entre aqueles senhores que preferiram abandonar suas terras e se retirar com família, agregados e escravos para Salvador, e aqueles que optaram por permanecer em suas propriedades e aceitar o novo governo (Mello, 1998, p. 33-39, 220; Serrão, 1968, p. 230-232).

Nessa conturbada cena viveu Jorge Lopes Brandão. Os registros de sua história - uma série de papeis do Conselho de Portugal em Madri - colocam-no bem no meio desses eventos: por esses registros sabemos que, nas primeiras décadas do século XVII, ele e seus irmãos comandavam propriedades que montavam a duzentos mil cruzados 
na Paraíba. Sabemos também que, durante o conflito com as tropas da WIC, alcançou a patente de capitão de infantaria e cavalaria, muito provavelmente - apesar de tal questão não estar posta nos documentos do Conselho - nas milícias formadas por Matias de Albuquerque. Por fim, as últimas informações que temos a seu respeito no Brasil afirmam que, após a invasão da Paraíba, ele e seus irmãos passaram a residir e lutar em Pernambuco até a retirada para a Bahia (Sobre lo que escribe Don Luis de Rojas cerca de las mercedes que se devem hacer a las personas que asisten en la guerra de Phernambuco dineros que se deven lhe dar, y perdon que se devem dar. AGS, Secretarías Provinciales, Libro 1478, hojas 37-39).

Assim, segundo seu retrato pintado pelos papeis oficiais, ele não apenas teria combatido, mas também financiado a guerra na Paraíba, mantendo-se sempre leal à Monarquia, apesar dessa obediência significar, na prática, o abandono e a perda de seus engenhos durante a retirada. No entanto, longe de ser um caso à parte, nessa situação de luta e perda ele integra um grupo bem amplo de senhores do açúcar que se empenharia, depois da guerra, em comprovar serviços e solicitar mercês. Homens como o capitão Domingos de Almeida que, em 1654, solicitou ao Conselho Ultramarino a patente de Sargento-mor da Paraíba pelos serviços prestados na guerra, dizendo ter sustentado muitos soldados durante a campanha naquela capitania, além de ter abandonado sua fazenda para acompanhar Bagnuolo "sem largar nunca o serviço da guerra" (Moura Filha, 2004, p. 43).

Na verdade, pouco havia de original nesses pleitos, que empregavam fórmulas discursivas muito comuns a quase todos os vassalos coloniais que solicitavam da Coroa - fosse Habsburga ou Bragança - mercês por serviços prestados nas guerras holandesas e que enfatizavam elementos tais como o investimento de recursos próprios no combate aos invasores, a continuidade na luta a despeito dos revesses e o abandono das propriedades uma vez perdida a batalha. Esse discurso, como já bem demonstrou Thiago Krause (2010, p. 33-35), quase não variava, reiterando constantemente o valor, as misérias passadas e o zelo dos veteranos na execução do serviço real.

E nesse amplo leque de petições se encaixam também, à primeira vista, aquelas solicitações de Jorge Lopes Brandão e sua família, que poderiam ser tomadas apenas como outras dentre as muitas solicitações padronizadas de mercês por serviços prestados se não fosse por sua presença nas batalhas espanholas da Guerra dos Trinta Anos. Um pouco antes disso, entretanto, ele já era assunto nos registros da Monarquia 
Católica referentes à queda da resistência luso-espanhola em Pernambuco e às consequências daquele evento.

Após a queda do Arraial do Bom Jesus, a Coroa mandara substituir Matias de Albuquerque por um novo comandante: o espanhol D. Luís de Rojas y Borja. E este, quando ainda em Lisboa, empreendera uma investigação sobre os senhores que lutavam do outro lado do Atlântico, movido talvez pela impressão de que a maneira de garantir sua boa aceitação - principalmente por estar substituindo o irmão deposto do donatário de Pernambuco -, era se assegurar que tais senhores recebessem mais mercês do que as que até então lhes estavam sendo concedidas. Por isso, e após auferir os resultados de seu inquérito, Rojas y Borja escreveu ao Conselho de Portugal solicitando mercês para os "beneméritos" que se haviam destacado na guerra, porque esses estariam pobres e cansados do longo esforço. Instava assim o Conselho a que lhe desse "um bom número de hábitos de Cristo", e outras tenças, capelas e pensões que ele pudesse repartir entre os senhores leais assim que aportasse no Brasil (Sobre lo que escribe Don Luis de Rojas cerca de las mercedes que se devem hacer a las personas que asisten en la guerra de Phernambuco dineros que se deven lhe dar, y perdon que se devem dar. AGS, Secretarías Provinciales, Libro 1478, hojas 37-39).

Rojas y Borja procurava, dessa maneira, garantir para si o poder de negociar e remunerar os senhores mazombos sem os quais a guerra seria impossível. Por isso argumentava com o Conselho que, para que esses personagens continuassem na guerra, era necessário lhes dar mais do que até então tinha sido feito, porque "só com cartas favorecidas não se pagam"; ou seja, era preciso compensar de forma mais concreta suas perdas. Argumento com o qual o Conselho de Portugal concordou após ter consultado outro dos comandantes de Pernambuco, o capitão-mor da Paraíba Antônio de Albuquerque, que chegara a listar aqueles senhores que considerava indiscutivelmente leais a Felipe IV. Uma lista que incluía o capitão Martim Soares Moreno, Jorge Lopes Brandão e seus parentes Luís Brandão e Francisco Camelo Brandão, que teriam perdido três engenhos e muitas fazendas e açúcares, os capitães Manuel Pires e Manuel Coresma Carneiro, ambos também com propriedades perdidas, Baltazar da Rocha Pitta; os capitães Jacinto de Siqueira Sampaio, Don Gaspar de Valcacer Sottomayor, Mateus Gomes de Lemos e Leonardo de Albuquerque, assim como o sargento-mor Antônio de Madureira, o ajudante Domingo Ramello Pinto, o alferes Antônio Álvares Pinheiro, e por fim Don Fernando de Alvarado, Marcos Pinto e Miguel Dias de Oliveira (AGS, Secretarías Provinciales, Libro 1478, hojas 37-39). 
Todos apresentados como merecedores de agradecimentos, uma vez que o resto da "gente nobre" teria se retirado da capitania assim que a oportunidade surgira.

Podemos encontrar referências a alguns desses personagens em outras fontes, o que possibilita o desenho de um esboço mais nítido daqueles que optaram por se manter leais ao rei após a invasão holandesa. Sabemos, por exemplo, que entre as décadas de 1610 e 1620 um Martin Soares Moreno, autor da Relação do Ceará, datada de 1618, esteve em expedição no Ceará, mais tarde sendo nomeado capitão-mor da fortaleza do Ceará (Martins, 2010, p. 22, 23,33). Impossível confirmar se é o mesmo personagem ou um homônimo, mas a periodização coincide com o Soares Moreno listado nos papeis do Conselho de Portugal, e quando notamos que em 1631 o já então capitão-mor do Ceará estava em Pernambuco comandando um contingente de índios e lutando baixo as ordens de Matias de Albuquerque (idem, p. 92-93), parece mais e mais plausível ser ele o Martim Soares mencionado por Antônio de Albuquerque. Mais plausível ainda quando percebemos que sua primeira expedição em 1603 partira sob o comando do tio, Diogo Campos Moreno, de Filipeia (Moura Filha, 2004, p. 57, 58).

Além dele, encontramos alusão ainda a um Manuel Quaresma Carneiro que em 1634 aparece como proprietário de dois engenhos nas margens do rio Paraíba, os engenhos São Jacob e São Felipe (ibid., p. 226), e a um Manuel Pires, chamado por Felipe III de fidalgo de minha casa, que servira na Ilha da Madeira até 1612 e depois na Paraíba como capitão do forte do Varadouro, em Filipeia. Um forte que ele mesmo construirá e sustentara e pelo que receberia algumas mercês regias (ibid., p. 177). Era também um senhor de engenho, comandando os engenhos Santo Antônio e Espírito Santo até estes serem tomados pelos invasores (ibid., p. 209, 226). Também Antônio de Madureira aparece em outros documentos, especificamente em um requerimento dirigido a Felipe IV solicitando a patente de sargento-mor em um terço nos Açores por serviços prestados na Paraíba (REQUERIMENTO de António de Madureira, ao rei [Filipe III], solicitando patente de sargento-mor do Terço que D. Diogo Lobo está levantando nas ilhas dos Açores, pelos serviços feitos na Paraíba e nas armadas reais. Arquivo Histórico Ultramarino (AHU), Paraíba, cx. 1, AHU_CU_014, Cx. 1, D. 26.).

Todos esses indícios falam de senhores de terra que, baixo o governo dos Felipes estiveram bastante ativos no processo de conquista das capitanias do norte a partir de Pernambuco, confirmando assim a afirmação do capitão Antônio de Albuquerque sobre os serviços 
prestados à Monarquia por esses personagens. E entre eles estava Jorge Lopes Brandão, ocupando posições de terratenente e comandante, papeis sociais integrados desde os primeiros ensaios de colonização, e atuando a favor da consolidação do poderio Habsburgo naquelas conquistas, ao mesmo tempo em que ampliava suas próprias propriedades e influência política.

Um outro ponto a considerar com relação a esses senhores diz respeito às autoafirmações de lealdade, consistentemente atreladas, durante e depois da guerra, à lembrança das perdas de fazendas, escravos e propriedades sofridas durante a invasão, sempre apregoadas como consideráveis. Tais reiterações de prejuízos se tornaram, de fato, uma fórmula discursiva utilizada constantemente em solicitações de remuneração e mercês pelos serviços prestados na guerra (Costa, 1985; Krause, 2010). E se tal discurso se tornou cada vez mais frequente no desenrolar do século XVII, isso se deveu à extrema valorização da tópica da lealdade por parte da Coroa. Uma tópica que, no caso dos vassalos da América portuguesa, era apregoada em associação direta com a perda de riquezas e revezes pessoais na guerra e que está patente na consulta de Rojas y Borja, que enfatizava a medida da lealdade dos senhores não apenas por sua participação ativa na luta, mas também pela presteza e boa vontade em abandonar suas propriedades, seguindo as ordens reais. Tudo em perfeita consonância com o imaginário cortesão para o qual a lealdade era a primeira exigência feita aos servidores do Rei na Corte, começando com os próprios validos e chegando até às mais distantes províncias do Império, e que deveria se traduzir, de forma prática, em serviços prestados ao rei (Kamen, 1995, p. 18; Barriera, 2011).

No caso de Jorge Lopes Brandão, às primeiras reiterações de sua lealdade, feitas por Antônio de Albuquerque, seguiram-se as apresentadas por seu irmão, Duarte Brandão, que em 1635 escreveu um memorial à Coroa solicitando mercês e compensações pelos serviços prestados e perdas sofridas por sua família, segundo um modelo literário já utilizado por Gabriel Soares de Souza com finalidade muito semelhante. Nesse texto, Duarte Brandão expunha o contexto já descrito por Rojas y Borja e Albuquerque e repetia as mesmas fórmulas que se tornariam comuns aos requerimentos dos veteranos do mundo do açúcar, oferecendo mais informações sobre sua família: apresentava Jorge Lopes Brandão, seu irmão, como Cavaleiro da Ordem de Cristo, Luís Brandão, também seu irmão, como capitão de infantaria, e seu sobrinho, Francisco Camelo Brandão, como fidalgo da Casa Real. Afirmava serem todos residentes em Pernambuco, no momento em que escrevia, e dizia terem perdido, 
com sua saída da Paraíba, mais de cento e cinquenta mil cruzados de rendimentos anuais. Não esquecendo também de mencionar o quão renomada a família se havia tornado por ter abandonado suas propriedades para seguir combatendo pela Coroa (Sobre lo que pide Duarte Brandão en nombre de sus hermanos Jorge Lopes Brandão; y de su sobrino Francisco Camelo Brandão: que se hallaron en la evasión de la Parahyba y dejaron todos sus haciendas per seguir el servicio de $V M g[d e]$. AGS, Secretarías Provinciales, Libro 1478, hj 51-51v).

Segundo ele, sua família teria investido de forma tal no conflito que teria passado pelo menos cinco anos sem produzir açúcar de forma significativa e comerciável. E esse esforço, ele afirma, teria sido a principal razão pela qual a praça teria se sustentado pelo tempo que o fizera, lembrando ainda a coragem e lealdade dos irmãos que haviam rejeitado muitas oportunidades de passar para o Reino abandonando a guerra. E por fim, nota, com a queda da capitania, seus irmãos não teriam hesitado em deixar para trás suas propriedades em mãos de inimigos e moradores, "siendo sin comparación las mayores q ningún particular poseía en la dicha capitanía", mudando-se para o Recife "adonde quedan sirviendo y pretenden acabar la vida en servicio de VMg" (AGS, Secretarías Provinciales, Libro 1478, hj 51-51v).

Uma descrição tal dos fatos, essa de Duarte Brandão, que foi aparentemente aceita sem ressalvas pelo Conselho de Portugal, e que incluiu a família entre os inúmeros veteranos que, após a guerra, iriam cobrar os serviços prestados à Coroa. Mas o que ela não mostra é que nem todos os irmãos Brandão permaneceram servindo em Pernambuco ou na Bahia por muito tempo após sua saída da Paraíba, já que, pouco depois, em 1638, Jorge Lopes Brandão seria encontrado lutando em Fuenterrabía.

Em tudo isso, entre cartas de comandantes, pedidos de irmãos e pareceres dos conselheiros em Madri, o retrato de Jorge Lopes Brandão se torna mais e mais nítido: um abastado senhor de engenho de uma capitania conquistada pelos Felipes, que não apenas lutara contra as tropas invasoras da companhia holandesa mas que chegara a financiar a resistência, e que já em 1635 ostentava o título de cavaleiro da Ordem de Cristo. E ainda que ele e seus irmãos se ressentissem da falta de um maior reconhecimento régio por seus serviços - ressentimento visível não tanto em seus pedidos de mercê mas principalmente na afirmação constante de que nada tinham até então recebido do rei - ele não parece ter desanimado muito e ainda na mesma década estaria lutando pela Monarquia Católica nos reinos espanhóis. 


\section{Jorge Lopes Brandão na Espanha}

A passagem de Jorge Lopes Brandão da Paraíba para Navarra pode ser inscrita entre os trânsitos impulsionados pela Monarquia Católica dentro de seu território e ilustra o alto grau de negociação entre o centro e as periferias dos impérios modernos, defendido por Bartolomé Yun Casalilla (2009, p. 12). Por outro lado, retrata também o que Antonio Moreno Almárcegui $(2009$, p. 43) considera como a função de atração e promoção social da Corte espanhola sobre as elites regionais de seus amplos territórios, visto que Jorge Lopes Brandão, apesar de colono português, seria atraído por Madri e não por Lisboa. A facilidade de circulação dentro dos domínios dos Habsburgo transparece no próprio fato de que, entre as décadas de 1630 e 1640, ele esteve envolvido na guerra de resistência da América portuguesa contra os holandeses, na etapa espanhola da Guerra dos Trinta Anos e na repressão à revolta da Catalunha. Todos importantes conflitos, definidores dos rumos políticos do império espanhol nas décadas seguintes. Já as negociações entre centro e periferia se traduzem em sua aceitação nos círculos da fidalguia graças a suas habilidades militares e aos recursos que oferecia às necessidades do rei. Por tudo isso, se seu histórico na Paraíba fala sobre estruturas sociais do mundo do açúcar, seu envolvimento nos conflitos espanhóis aponta para as possibilidades de assimilação das elites regionais das periferias imperiais pela corte dos Habsburgo em um momento onde essa corte se via desafiada por diferentes contendores.

O cenário da Espanha no século XVII era de crise, já bastante estudada pela historiografia (Maravall, 1997; Elliot, 2007; Lynch, 2005; Parker, 2005), com crescentes desassossegos políticos internos, atrelados ao escalonamento do envolvimento espanhol em conflitos externos. A necessidade de aumento das tropas, associada à minguante situação dos cofres espanhóis, levou o Conde-Duque Olivares a propor, como resposta, a chamada União de Armas, uma estratégia defensiva para todo o território espanhol, desenhada de forma a que cada um dos reinos pertencentes à Coroa dos Felipes contribuísse para com os gastos militares da Monarquia e que visava desafogar as já muito desgastadas finanças de Castela. Uma proposta que não apenas não prosperou, como chegou mesmo a se somar aos desentendimentos e rancores que culminariam na independência de Portugal e na revolta da Catalunha em 1640 (Elliott, 2006, p. 357-360). E se os reinos da Coroa espanhola terminaram mesmo, em sua maior parte, por contribuir com homens, dinheiro e outros recursos para as guerras da Coroa, não o 
fizeram sem oferecer muita resistência, principalmente a Catalunha que se negou a enviar recursos e tropas mesmo quando os franceses sitiaram Fuenterrabía em 1638 (Lynch, 2005, p 100-101).

E assim os custos maiores com a Guerra dos Trinta Anos, também em solo espanhol, terminaram mesmo por recair sobre Castela (Hernandez Franco; Molina Punche, 2004, p. 112; e Vila Lopez, 1979, p. 126). O que não impediu que a situação política da Coroa perante algumas de suas elites provinciais, principalmente catalães e portugueses, piorasse consideravelmente. Segundo Dominguez Ortíz, enquanto a guerra permaneceu em territórios longínquos e se podia lutar com mercenários, os problemas internos pareceram a todos contornáveis, mas quando os franceses cercaram Fuentarrabía a situação começou a mudar. Apesar disso, nesse cerco as divergentes forças políticas que fragmentavam a Monarquia Católica foram temporariamente amenizadas pela cooperação contra os invasores: isso porque, com as melhores tropas espanholas envolvidas em outros conflitos, Olivares conseguiu uma nova grande mobilização militar interna, arrebanhando soldados de toda parte, desde a guarnição de Granada. Por outro lado, Fuenterrabía inspirou uma mobilização popular espontânea contra a invasão que acudiu o governo por um tempo (Ortiz, 2000, p. 168).

Mas apesar dessa última mobilização, que incluiu fidalgos de diferentes origens, ilustrando a diversidade regional então corriqueira nos terços da Monarquia Católica, a grande maioria dos homens que lutaram nas fronteiras navarras eram mesmo navarros e aragoneses (Rodriguez Gazarra, 1991). E se Aragão, como outros reinos espanhóis, havia relutado em contribuir com a movimentação para a guerra em outros territórios, a chegada do conflito a suas fronteiras obrigou esse reino não apenas a mobilizar homens e recursos, mas também a servir de guarnição para as tropas dos Habsburgo. Uma situação que causou ainda mais desgaste onde as finanças já estavam bastante desgastadas (Colas Latorre, 1978, p. 06-07; e Hernández Franco; Molina Puche, 2004, p. 112), e que criou tensões internas tais na sociedade espanhola que levaria a Coroa a tentar revitalizar a função bélica da nobreza; uma função já bem enfraquecida em Castela (Hernández Franco; Molina Puche, 2004, p. 113).

Por tudo isso, o cerco que as forças de Luís XIII impuseram a Fuenterrabía em 1638 foi um dos marcos principais da Guerra dos Trinta Anos na Espanha, tanto por levar a guerra para dentro dos reinos espanhóis, quanto pelo fato de que, até então, também os navarros haviam hesitado em se unir à luta contra os franceses (ibid., p. 112). 
Só quando o castelo dessa cidade, peça fundamental na linha de defesa do reino, foi cercado pelos vinte mil homens enviados por Condé, o Vice-Rei de Navarra foi finalmente capaz de convencer as elites locais a colaborar (Usunáriz Garayoa, 2007, p. 290, 311-312).

$\mathrm{E}$ foi quando esse Vice-Rei iniciou a convocação para as tropas que deveriam levantar o cerco ao castelo que nosso personagem, Jorge Lopes Brandão, se viu envolvido nos conflitos. Então já na Espanha, ele solicitou ao rei que lhe permitisse se unir aos fidalgos portugueses que lutavam em Navarra. A Coroa, que se via às voltas com a relutância de sua própria nobreza em combater, aceitou seu pedido, demonstrando boa receptividade para com seus vassalos estrangeiros, principalmente quando estes eram práticos de guerra. Assim, não muito tempo após ter abandonado a Paraíba, e apenas três anos após a queda do Arraial Velho do Bom Jesus, esse senhor de engenho lutava ao lado da nobreza navarra contra os franceses nas fronteiras espanholas. Mas não pararia por ai, já que pouco depois estaria entre os fidalgos portugueses recrutados para atuarem na repressão à revolta catalã, para a qual teria, inclusive, contribuído com recursos próprios (Para el Secretrario Juan Baptista Saens Navarrette. Archivo General de Simancas (AGS), Secretarías Provinciales, Libro 1528, hoja 01-01v.).

Essa trajetória fala das possibilidades e formas pelas quais os senhores do açúcar poderiam ser aceitos pela Coroa espanhola: sua apresentação nos documentos do Conselho como "cavaleiro português" sugere que os mazombos chegavam à corte espanhola inseridos entre os números da nobreza portuguesa. Uma sugestão corroborada pela trajetória espanhola de outras famílias originárias de Pernambuco, como os Albuquerque Coelho (Dutra, 1973). Nesse sentido, talvez Jorge Lopes Brandão fosse mais identificado pela Coroa espanhola como um pequeno fidalgo português do que como integrante de uma elite colonial. De fato, por ocasião da rebelião da Catalunha, ele portava o título de Moço Fidalgo da Casa Real portuguesa (AGS, Secretarías Provinciales, Libro 1528, hoja 01-01v), que então ainda era reclamada por Felipe IV.

Por outro lado, sua folha de serviço de doze anos atuando como capitão de Infantaria e de Cavalos no Brasil - que inclusive lhe valera uma nomeação para governador do Maranhão, que nunca assumira devido à queda de Pernambuco (AGS, Secretarías Provinciales, Libro 1528, hoja 01-01v) -, além do serviço em Navarra e na Catalunha, permitem sua identificação enquanto um prático de guerra; um tipo constantemente requisitado pela Coroa espanhola. As reiteradas recomendações feitas a seu favor pela Coroa aos comandantes espanhóis em Navarra estavam 
bem de acordo com a política da Monarquia Católica de assimilação dos práticos de guerra portugueses. Essa circunstância não era uma novidade e também Portugal pós-restauração faria uso de práticos de guerra com experiência nos intermináveis conflitos do Império Habsburgo; personagens como Matias de Albuquerque e Vasco de Mascarenhas (Bebiano, 1993, p 83-98). E também não era sem precedentes que senhores mazombos fossem recomendados para ir servir no reino: o próprio Matias de Albuquerque já fizera essa recomendação a Felipe IV, e no pós-restauração também Francisco de Brito Freyre, governador de Pernambuco, a repetiria a D. João IV (Silva, 2001, p. 87). Jorge Lopes Brandão é um exemplo de que essas recomendações foram, de fato, levadas a sério pela Coroa Habsburga.

De forma geral, se não é possível olharmos Jorge Lopes Brandão, em suas andanças pela Espanha, como retrato da grande maioria dos senhores do açúcar nos seiscentos, também não devemos pensá-lo como um caso único, pois se Gruzinski (2010) já ressaltou os muitos trânsitos dentro dos territórios da Monarquia Católica, inclusive partindo das colônias para a Espanha e não apenas em sentido contrário, enfatizando os muitos criollos que saíam da América para a Corte "para realizar estudios, proseguir su carrera o publicar libros", a mesma situação também já era familiar ao mundo do açúcar antes de Brandão: do senhor de engenho Gabriel Soares de Souza que saiu do Brasil para a corte madrileña em busca de mercês e que terminou, no processo, por escrever um tratado (Raminelli, 2008, p. 58), a Bernadino Pessoa de Almeida, filho de senhor de engenho, que saiu das capitanias do norte do Estado do Brasil para estudar medicina em Salamanca e que mais tarde voltaria para sua região natal (Dios, 1976, p. 215-229).

Além deles, outros personagens aparecem na documentação deixada pela Coroa nos arquivos espanhóis e que são representativos dessas ligações entre os senhores de engenho da América açucareira portuguesa e a Casa dos Áustrias. Personagens como a família Mendoza, natural de Pernambuco, com vários membros agraciados com hábitos de cavaleiros da prestigiosa Ordem de Calatrava. Encontramos dois processos relativos a D. Bartolomé de Mendoza nos arquivos do Consejo de Ordenes, no Archivo Historico Nacional de España, e um relativo a seu irmão, D. Jerônimo de Mendoza (MENDOZA de Mendoza, Bartolomé de. OMEXPEDIENTILLOS, N.10316, Archivo Histórico Nacional de España; MENDOZA de Mendoza, Bartolomé de. OM-Caballeros_Calatrava, exp. 1618, fecha 1645. Consejo de Ordenes. Archivo Histórico Nacional de España; MENDOZA de Mendoza, Jerónimo de. OM-CABALLEROS 
CALATRAVA, Exp.1620. Archivo Histórico Nacional de España). Três processos que oferecem muitas pistas sobre a passagem dos senhores mazombos na Espanha pós-restauração, e que lançam luz também sobre a própria trajetória de Jorge Lopes Brandão. Pois neles vemos esses cortesãos, que ainda se apresentavam como naturais de Pernambuco, estabelecerem sua limpeza de sangue a partir dos cargos de prestígios e dos serviços militares que os membros da família haviam ocupado no Estado do Brasil

O processo de D. Jerônimo de Mendoza, por exemplo, deixa claro que a concessão desses hábitos estava em consonância com a política de ordenação como remuneração por serviços militares prestados. Nele vemos que D. Jerônimo já havia recebido, em 1642, um certificado do rei que lhe concedia o hábito da Ordem de Santiago, "con calidad expresa que aya de servirme la campaña deste año en el Vatallón de la Cavallería de las dhas ordenes" (MENDOZA de Mendoza, Jerónimo de. OM-CABALLEROS_CALATRAVA, Exp.1620. Archivo Histórico Nacional de España). Sua situação, assim, não estava longe da de Jorge Lopes Brandão, já que ambos estavam inseridos naquela categoria, a dos práticos de guerra, extremamente presada na Península Ibérica seiscentista, e tema constante de diversos comandantes portugueses e espanhóis que haviam servido no Brasil. Por outro lado, se esses celebrados serviços militares funcionavam como elementos chave em suas nobilitações, sua riqueza também não deve ter sido um fator a ser desprezado: no caso específico da família de Jorge Lopes Brandão, esta era senhora de muitos engenhos, e apesar das muitas afirmações sobre as perdas de suas propriedades, a própria atuação desse personagem em Navarra e na Catalunha demonstra que ele ainda matinha consideráveis rendas que o sustentaram, bem armado, nessas contendas.

Lopes Brandão se inseria, assim, em uma cena complexa de senhores de engenho e fidalgos, que ainda permanece em grande parte por ser descortinada. E que o Conselho de Portugal o tinha em alta conta parece ser fato, assim como também parece certo que ele tinha consciência desse apreço e que avaliava bem os serviços que prestara ao rei Habsburgo. Serviços por conta dos quais chegara mesmo a pedir o posto de cavalariço da Casa Real de Castela (AGS, Secretarías Provinciales, Libro 1528, hoja 01-01v). Infelizmente, não encontramos resposta para esse pedido, apesar de que só o fato de que tenha chegado a fazer tal requisição é um indicativo não somente de sua própria percepção acerca do valor de seus serviços, mas também da receptividade da Monarquia Católica com relação aos estrangeiros dentro de sua corte (Mesa, 2007, p. 85). 


\section{Considerações Finais}

Serge Gruzinski (2010, p. 47) já defendeu ser a Monarquia Católica um personagem tão complexo e difícil de interpretar quanto o Mediterrâneo de Braudel, e a história de Jorge Lopes Brandão parece concordar com essa afirmação, apresentando-se como um fragmento de um intrincado quadro de tramas políticas e culturais que envolvia a elite açucareira em um contexto intercontinental.

E é a complexidade desse cenário que ainda deixa muita coisa aberta à conjectura: os vínculos da elite açucareira com Madri, por exemplo, que sugerem que a política espanhola era mais significativa no mundo açucareiro colonial do que o suposto até agora. E que, além disso, também podem apontar a própria receptividade da Monarquia Católica, acostumada a amparar muitos refugiados católicos em sua corte; receptividade aqui refletida nos senhores do açúcar. Ruiz Ibañez chega a defender a existência de uma hispanofilia tanto na Europa quanto nos confins do Império no século XVII, baseada principalmente na política assistencialista dos Felipes para com os católicos estrangeiros. Segundo ele, milhares teriam atravessado as fronteiras do império "por vários motivos que parecem entrelaçados de maneira natural e cuja leitura global permite compreender o que significou, fora de suas fronteiras, a hegemonia do rei Católico" (Ibañez, 2011, p. 107-111). Essa recepitivade certamente se extendeu aos senhores do açúcar, ainda que talvez menos pelo assistencialismo defendido por Ibañez do que por um pragmatismo na vontade de usar os práticos de guerra lusoamericanos nos conflitos espanhois.

Essas conexões intercontinentais representadas pela trajetória de Brandão, por sua vez, correm em paralelo ao próprio contexto local de formação das elites açucareiras no século XVII e permitem que consideremos os senhores de engenho da América portuguesa para além daqueles circuitos já estudados pela historiografia brasileira. Assim, ao lado das investigações que analisam as elites açucareiras em relação ao comércio atlântico, assim como as câmaras municipais americanas ou as irmandades leigas, consideramos necessário pensá-las também dentro das políticas dos Felipes e como elementos constituintes da complexa estrutura de elites provinciais no Império espanhol, bastante acostumadas às brechas e negociações que tiravam da Coroa dos Habsburgo o caráter absoluto (Gil Pujol, 1991, p. 123-128). Pois, ao surgirem como personagens da Monarquia Universal, os senhores mazombos da América açucareira portuguesa abrem novos caminhos 
para a investigação das conexões entre centros imperiais modernos e suas periferias em ebulição.

Por sua vez, é preciso considerar as razões das lealdades, tão apregoadas e valorizadas, dos senhores dessas periferias ao centro imperial espanhol. No caso de Jorge Lopes Brandão, os favores conseguidos por ele junto ao rei explicam sua permanência do lado espanhol mesmo após a restauração portuguesa. Por outro lado, se esses favores estavam atrelados a sua função militar, também estavam bastante vinculados a sua identificação enquanto fidalgo português, e talvez mesmo à fidalguia colonial. Sem essa identificação, sua aceitação na corte seria inviável. Entretanto, uma conexão política com a nobreza luso-espanhola surge, nessas reflexões, cada vez mais como um dos fatores principais que podem explicar a ampla receptividade que nosso personagem encontrou nas fileiras fidalgas durante a Guerra dos Trinta Anos e a rebelião da Catalunha, muito mais do que seus serviços militares prestados na Paraíba. Pois se os práticos de guerra eram muito valorizados, isso não era suficiente para justificar sua ascensão social à fileira dos cavaleiros portugueses durante o governo Habsburgo.

Por tudo isso, a trajetória de Brandão entre a Paraíba e a Catalunha serve como esboço inicial de um quadro que ainda precisa ser desenhado, e que retrata as intricadas relações entre os senhores da América açucareira e a corte habsburga no cenário global da Monarquia Católica.

\section{Referências}

ALMÁRCEGUI, Antonio Moreno. La Población Española 1500-1860. In: FLORISTÁN, Alfredo (Coord.). Historia de España en Edad Moderna. Madrid: Ariel, 2009.

BARRIERA, Darío. A Lealdade dos Traidores: Rebelião, Justiça e Bom Governo no Rio da Prata (1580). In: MONTEIRO, Rodrigo B.; FEITLER, Bruno; CALAINHO, Daniela; FLORES, Jorge (Org.). Raizes do Privilégio-Mobilidade Social no Mundo Ibérico do Antigo Regime. Rio de Janeiro: Civilização Brasileira, 2011. p. 165-204.

BEBIANO, Rui Bebiano. Literatura Militar da Restauração. Penélope, Lisboa, n. 9/10, p. 83-98, 1993.

BouZA AlvareZ, Fernando. Portugal no tempo dos Filipes. Politica, Cultura, Representações (1580-1668). Lisboa: Cosmos, 2000.

BRAUDEL, Fernand. El Mediterráneo y el mundo mediterráneo en la época de Felipe II. Mexico: Fondo, 2001 [ $1^{\text {a }}$ ed. en castellano 1953].

COLAS LATORRE, Gregorio. Los Valles Pirenaicos Aragoneses y Su Colaboración con la Monarquía en la Defensa de la Frontera (1635-1643). Argensola: Revista de Ciencias Sociales del Instituto de Estudios Altoaragoneses, n. 85, p. 5-24, 1978. 
COSTA, Cleonir Xavier de Albuquerque da Graça e. Receita e despesa do Estado do Brasil no Período Filipino: Aspectos Fiscais da Administração Colonial. 1985, Recife, Dissertação (Mestrado em História) - Universidade Federal de Pernambuco, Recife.

DIOS, Angel Marcos de. Estudiantes de Brasil en La Universidad de Salamanca durante los siglos XVI y XVII. Separata da Revista de História, São Paulo, n. 105, 1976. p. 215-229.

DUTRA, Francis. Notas sobre a Vida e Morte de Jorge de Albuquerque Coelho e a Tutela de seus filhos. Separata da Stvdia - revista semestral, Lisboa, Centro de Estudos Históricos Ultramarinos, n. 37, p. 265-267, dez. 1973.

ELLIOTT, John H. . España y su Mundo. Madrid: Taurus, 2007 [1ª ed. 1991].

ELLIOTT, John H. La España Imperial 1469-1716. Madrid: Biblioteca Historia de España, 2006.

FIGUEIREDO, Luciano. Tensões e rebeliões: a nobreza da terra à sombra do Novo Mundo. In: Actas do Congresso Internacional Pequena Nobreza nos Impérios Ibéricos de Antigo Regime. Edição digital. Lisboa: Instituto de Investigação Científica Tropical Centro de História de Além-Mar, 2012. v. 1, p. 1-9.

FRANÇA, Eduardo D’Oliveira. Portugal na Época da Restauração. São Paulo: Hucitec, 1997.

GIL POJUL, Xavier. Centralismo e Localismo? Sobre as Relações Políticas e Culturais entre Capital e Territórios nas Monarquias Europeias dos Séculos XVI e XVII. Penélope - Fazer e Desfazer Historia, v. 6. p. 119-144, 1991.

GONÇALVES, Regina C. Guerra e Açúcar: A Formação da Elite Política na Capitania da Paraíba (Séculos XVI e XVII). In: OLIVEIRA; MEDEIROS (Org.). Novos Olhares sobre as Capitanias do Norte do Estado do Brasil. João Pessoa: Ed. UFPB, 2007. p. 23-67.

GONÇALVES, Regina C. O Capitão-Mor e o Senhor de Engenho: os conflitos entre um burocrata do rei e um 'nobre da terra' na Capitania Real da Paraíba (Século XVII). In: Actas do Congresso Internacional Espaço Atlântico de Antigo Regime: poderes e sociedades. Lisboa: Instituto Camões, 2008. v. 1, p. 1-14.

GRUZINSKI, Serge. Las Cuatro Partes del Mundo: Historia de una Mundialización. México: FCE, 2010.

GRUZINSKI, Serge. O Historiador, o Macaco e a Centaura: a História Cultural no Novo Milênio. Estudos Avançados, v. 17, n. 49, 2003.

HERNANDEZ FRANCO, Juan; MOLINA PUCHE, Sebastián. El retraimiento militar de la nobleza castellana con motivo de la guerra franco-española (1635-1648). El ejemplo contrapuesto del Reino de Murcia. Cuadernos de Historia Moderna, n. 29, p. 111-130, 2004.

KAMEN, Henry. O Estadista. In: VILLARI, Rosario (Org.). O homem barroco. Lisboa: Editorial Presença, 1995.

KRAUSE, Thiago N. Em busca da honra: a remuneração dos serviços da Guerra Holandesa e os hábitos das Ordens Militares (Bahia e Pernambuco, 1641-1683). 2010, Rio de Janeiro. Dissertação (Mestrado em História) - Universidade Federal Fluminense, Rio de Janeiro, 2010.

LYNCH, John (Dir.). Historia de España. Madrid: Critica, 2005. Vol. 5: Edad Moderna. Crisis y recuperación, 1598-1808. 
MARAVALL, José Antonio. A cultura do barroco - análise de uma estrutura histórica. São Paulo: Edusp/Imprensa Oficial, 1997.

MARTINS, Guilherme Saraiva. Entre o Forte e a Aldeia: estratégias de contato, negociação e conflito entre europeus e indígenas no Ceará holandês (1630-1654). 2010, Fortaleza. Dissertação (Mestrado em História) - Universidade Federal do Ceará, Fortaleza, 2010.

MEGIANI, Ana Paula. O Rei ausente - festas e cultura política nas visitas dos Felipes a Portugal (1581-1619). São Paulo: Alameda, 2004.

MELLO, Evaldo Cabral de. Olinda restaurada - guerra e açúcar no Nordeste, 16301654. Rio de Janeiro: Topbooks, 1998.

MOURA FILHA, Maria Berthilde de B. L. De Filipéia à Paraíba: uma cidade na estratégia de colonização do Brasil. 2004, Porto. Tese (Doutorado em História) Universidade do Porto, Porto, 2004.

NASCIMENTO, Rômulo L. X. O desconforto da governabilidade: aspectos da administração do Brasil holandês (1630-1644). 2008, Rio de Janeiro. Tese (Doutorado em História) - Universidade Federal Fluminense, Rio de Janeiro, 2008.

ORTIZ, A. D. España, tres Milenios de Historia. Madrid: Marcial Pons, 2000.

PARKER, Geoffrey. The General Crisis of the Seventeenth Century. 2. ed. London and New York: Routledge, 2005.

RAMINELLI, Ronald Raminelli. Viagens ultramarinas - monarcas, vassalos e governo a distância. São Paulo: Alameda, 2008.

RODRIGUEZ GARRAZA, R. Navarra y la Administración Central (1637-1648). Cuadernos de Historia Moderna, Madrid: Edit. Univer. Complutense, n. 11, p. 149-176, 1991.

RUIZ IBAÑEZ, José Javier. Servir Segundo a Dignidade: Exílios Políticos e Administração Real na Monarquia Hispânica, 1580-1610. In: MONTEIRO, Rodrigo B.; FEITLER, Bruno; CALAINHO, Daniela; FLORES, Jorge (Org.). Raízes do privilégio - Mobilidade Social no Mundo Ibérico do Antigo Regime. Rio de Janeiro: Civilização Brasileira, 2011. p. 105-132.

SANTOS PÉREZ, José Manuel. A estratégia dos Habsburgo para a América portuguesa. Novas propostas para um velho assunto. In: ALMEIDA et al. (Org.). Politicas e estratégias administrativas no mundo Atlântico. Recife: Ed. Universitária da UFPE, 2012. p. 239-246.

SCHMIDT, Peer. La Monarquía Universal Española y América - la imagen del Imperio español en la Guerra de los Trinta Años (1618-1648). México: Fondo, 2013.

SERRÃO, Joaquim Veríssimo. Do Brasil Filipino ao Brasil de 1640. São Paulo: Companhia Editora Nacional, 1968.

SILVA, Kalina Vanderlei. O miserável soldo \& a boa ordem da sociedade colonial militarização e marginalidade na Capitania de Pernambuco nos séculos XVII e XVIII. Recife: FFCR, 2001.

SORIA MESA, Enrique. La nobleza en la España moderna. Madrid: Marcial Pons, 2007.

USUNÁRIZ GARAYOA, Jesús M. Soldados, sociedad y política en un reino de frontera: Navarra siglos XVI y XVII. Iura Vasconiae, n. 4, p. 285-325, 2007. 
VALLADARES, Rafael. A independência de Portugal: guerra e restauração: 16401680. Lisboa: A Esfera dos Livros. 2006.

VILA LÓPEZ, Margarita. La Aportación Valenciana a la Guerra con Francia (1635640). Estudis: Revista de historia moderna, Universidad de Valencia, n. 08, p. 125-142, 1979.

YUN CASALILLA, Bartolomé. Entre el Imperio Colonial y la Monarquía Compuesta. Élites y Territorios en la Monarquía Hispánica (ss. XVI y XVII), In: YUN CASALILLA, Bartolomé (Dir.). Las redes del Imperio - élites sociales en la articulación de la monarquía hispánica, 1492-1714. Madrid: Marcial Pons, 2009. p. 11-35.

\section{Fontes manuscritas e impressas}

MENDOZA de Mendoza, Bartolomé de. OM-EXPEDIENTILLOS, N.10316, Archivo Histórico Nacional de España.

MENDOZA de Mendoza, Bartolomé de. OM-Caballeros_Calatrava, exp. 1618, fecha 1645. Consejo de Ordenes. Archivo Histórico Nacional de España.

MENDOZA de Mendoza, Jerónimo de. OM-CABALLEROS_CALATRAVA, Exp.1620. Archivo Histórico Nacional de España.

PARA el Secretrario Juan Baptista Saens Navarrette. Archivo General de Simancas (AGS), Secretarías Provinciales, Libro 1528, hoja 01-01v.

REQUERIMENTO de António de Madureira, ao rei [Filipe III], solicitando patente de sargento-mor do Terço que D. Diogo Lobo está levantando nas ilhas dos Açores, pelos serviços feitos na Paraíba e nas armadas reais. Arquivo Histórico Ultramarino (AHU), Paraíba, cx. 1, AHU_CU_014, Cx. 1, D. 26.

SOBRE lo que escribe Don Luis de Rojas cerca de las mercedes que se devem hacer a las personas que asisten en la guerra de Phernambuco dineros que se deven lhe dar, $y$ perdon que se devem dar. Archivo General de Simancas, AGS, Secretarías Provinciales, Libro 1478, hojas 37-39.

SOBRE lo que pide Duarte Brandão en nombre de sus hermanos Jorge Lopes Brandão; $y$ de su sobrino Francisco Camelo Brandão: que se hallaron en la evasión de la Parahyba y dejaron todos sus haciendas per seguir el servicio de VMg[de], Archivo General de Simancas, AGS, Secretarías Provinciales, Libro 1478, hj 51-51v.

SUMARIO das Armadas [1585]. In: Revista Municípios em Destaque, Rio de Janeiro ano XVII, n. 69, p. 17-20 e p. 51-60, 1996, apud <http://www.carlamaryoliveira. pro.br/>. 